\title{
Purification and characterization of Kunitz trypsin inhibitor from soybean
}

\author{
Chunmei Gu*1,a, Shujun $\mathrm{Li}^{1, \mathrm{~b}}$ and Xinxiu Song ${ }^{1, \mathrm{c}}$ \\ ${ }^{1}$ Institute of Food Science and Engineering, Jilin Agricultural University, Changchun 130118,China \\ a jjnong2008@126.com, , b648112081@qq.com, ${ }^{c}$ 519038276@qq.com \\ * Corresponding author
}

\begin{abstract}
Keywords: soybean; Kunitz trypisin inhibitor; purification; characterization
Abstract. In this paper, a Kunitz trypsin inhibitor from soybean meal was isolated to apparent homogeneity by a combination of phosphoric acid extraction, heat treatment, ammonium sulfate precipitation, ion exchange chromatography, affinity chromatography and gel filtration. The results showed that the specific activity of $4733 \mathrm{U} \cdot \mathrm{mg}^{-1}$ and purification fold of 72.39 were obtained. The purified Kunitz trypsin inhibitor appeared a single protein band in SDS-PAGE electrophoresis. The accurate molecular mass of this inhibitor was determined as 22907.51Da by MALDI-TOF. Partial amino acid sequence of the purified protein from Edman degration showed a high degree of homology with various members of the Kunitz-inhibitor family.
\end{abstract}

\section{Introduction}

Proteinase inhibitors (PIs) are widespread anti-nutrient substances in many plants, particularly the legumes which are rich in proteins or peptides with capacity of inhibiting the catalytic activity of proteolytic enzymes. Legume seeds contain Kunitz and Bowma-Birk families. Kunitz inhibitor (KTI) is protein with $20 \mathrm{kDa}$, and contains 181 amino acid residues which have two disulfide bonds (Cys39-Cys86 and Cys136-Cys145) and owns a single arginine residue reaction site [1]. In addition, the Kunitz-type soybean trypsin inhibitor is relatively sensitive to heat and acid and a molecule of KTI blocks a molecule of trypsin or chymotrypsin [2].

Many studies have been performed for the purification of KTI in recent years, such as, Kakade et al. [3] firstly developed the KTI extraction method in 1974, but the yield and purity of KTI was not high. Over the past few years, many efforts have been made to purify the SKTI, for example, the method based on the combination of several different chromatography [4], the method using preparative electrophoresis [5], and others employing immobilized metal affinity chromatography [6]. However, these methods had complicated separation process and low purification factor. In addition, a high-efficiency, convenient purification process of SKTI will be beneficial to studies on their biological properties and applications in different fields, such as nutrition, medicine, and agriculture [7-10]. Therefore, this study will develop a method with the practical significance for purifying SKTI.

\section{Materials and Methods}

Materials. Soybean was provided by Jilin Academy of Agricultural Sciences, in Jilin, Changchun, China. Trypsin and BAPNA (N-benzoyl-DL-arginine-p-nitroaniline hydrochloride) were obtained by Shanghai Sanjie Biotechnology Co, in Shanghai, China. Trypsin-sepharose 4B, DEAE-cellulose DE-52 and Sephadex G-75 were obtained by Beijing Ruida Henghui Science and Technology Development Co, in Beijing, China. Marker (mid) was obtained by Beijing Dingguo Changsheng Biotechnology Co, in Beijing, China.

\section{Extraction and Purification of KTI.}

Preparation for crude extract of KTI. After the soybean seeds skin were removed, the seeds were finely ground, defatted with petroleum ether, and then extracted by 10 volumes of $0.1 \mathrm{M}$ phosphate buffer (pH7.6) and meanwhile stirred with a magnetic stirrer. The extract was centrifuged at $10000 \mathrm{rpm}$ min-1 for $20 \mathrm{~min}$ (the same below). The supernatant was incubated in water at $65^{\circ} \mathrm{C}$ for 
10min and then centrifuged. Solid $\left(\mathrm{NH}_{4}\right)_{2} \mathrm{SO}_{4}$ and ammonium sulfate were respectively added to the supernatant in order to get $35 \%$ and $75 \%$ saturation at $4{ }^{\circ} \mathrm{C}$ for 2 hours. The precipitate was obtained by centrifuging and again dissolved in a small volume of deionized water, and then dialyzed with buffer A (50 mM of Tris-HCl, pH8.0) for 24 hours and freeze-dried sample was used for purification of SKTI [11].

Purification of soybean trypsin inhibitor. This assay was performed by the method of Rackis and Anderson [12] with the slight modification. The crude sample was dissolved in buffer A, and then applied to DEAE-cellulose column that was previously equilibrated with buffer A [12]. It was washed with buffer A after the column reloaded the sample for three times. Then protein absorbed to column performed a linear gradient elution at a flow rate of $0.5 \mathrm{ml} / \mathrm{min}$ and $0-0.4 \mathrm{M} \mathrm{NaCl}$ in the same buffer was used as the eluent. Absorbance was recorded at $280 \mathrm{~nm}$. The fractions with TI activity were combined, dialyzed with buffer B $\left(100 \mathrm{mM}\right.$ Tris- $\mathrm{HCl}, \mathrm{pH} 8.0$ containing $\left.0.02 \mathrm{~mol} / \mathrm{LCaCl}_{2}\right)$ and then attached a trypsin-Sepharose $4 \mathrm{~B}$ column $(1.3 \times 15 \mathrm{~cm})$ that was balanced with buffer $\mathrm{B}$. Then affinity column was washed with buffer B and protein absorbed to column was eluted with $100 \mathrm{mM} \mathrm{HCl}$ at $30 \mathrm{ml} / \mathrm{h}$ of flow rate, followed by neutralization with $2 \mathrm{M}$ Tris. The fractions with TI activity were combined, dialyzed with buffer $\mathrm{C}(100 \mathrm{mM}$ phosphate buffer, $\mathrm{pH} 7.6$ containing $100 \mathrm{mM} \mathrm{NaCl})$ and concentrated by the use of polyethylene glycol 20000. Finally, the purified proteins was applied to Sephadex G-75 column $(1.5 \times 100 \mathrm{~cm})$ which was balanced with buffer C in $1.0 \mathrm{ml}$ fractions at $15 \mathrm{ml} / \mathrm{h}$ of flow rate. And then the fractions with TI activity were combined and concentrated by the use of polyethylene glycol 20000 for further application.

Assay of inhibitory activity. Trypsin inhibitory activity was measured according to the reports of Johnson et al. [13]. by estimated remaining ester hydrolysis of trypsin activity towards to the substrate BAPNA. Before trypsin reacted with the substrate BAPNA, it was firstly incubated with KTI in $0.05 \mathrm{M}$ Tris- $\mathrm{HCl}$ buffer $\left(\mathrm{pH} 8.0,0.02 \mathrm{M} \mathrm{CaCl}_{2}\right)$ for $5 \mathrm{~min}$ at $37^{\circ} \mathrm{C}$. Then trypsin inhibitory activity was estimated by the esterolytic activity of trypsin to BAPNA. One unit of trypsin enzyme activity of (TU) is defined as 0.01 of the increase in absorbance at $410 \mathrm{~nm}$.

Estimation of proteins. Protein concent was measured by the method reported by Brandford [14] and BSA was used as standard protein. Protein content of each fraction collected from every step was measured by the absorbance at $280 \mathrm{~nm}$.

SDS-PAGE electrophoresis. The sample for experiment was collected in $500 \mathrm{~mL}$ of buffer (92 $\mathrm{mM}$ of Tris- $\mathrm{HCl}, \mathrm{pH} 8.1,23 \mathrm{mM}$ of $\mathrm{CaCl}_{2} \cdot 2 \mathrm{H}_{2} \mathrm{O}, 20 \%$ of sucrose). The extract was centrifuged at 1000 r.min ${ }^{-1}$ for $15 \mathrm{~min}$. And then, the resulting supernatant $(60 \mu \mathrm{L})$ was added to $30 \mu \mathrm{L}$ of sample buffer $(0.06 \mathrm{M}$ of Tris-HCl, pH 6.8, 25\% of glycerol, $2 \%$ of SDS, $0.0144 \mathrm{M}$ of mercaptoethanol, $0.1 \%$ bromophenol blue) and boiled in boiling water at $100{ }^{\circ} \mathrm{C}$ for $3 \mathrm{~min}$. Electrophoresis experiment was started. The one-dimensional SDS-PAGE was measured as described by Laemmlide method [15]. The stacking gel used in the experiment contained $5 \%$ of acrylamide-bisacrylamide in $0.5 \mathrm{M}$ Tris- $\mathrm{HCl}$ buffer (pH6.8) and 0.4\% SDS. 12\% SDS-polyacrylamide gel was used to separate the proteins. The running buffer contained $0.5 \mathrm{M}$ Tris- $\mathrm{HCl}$ buffer $(\mathrm{pH} 8.8), 1.92 \mathrm{M}$ glycine and 1\% SDS. Electrophoresis began at voltage of $80 \mathrm{~V}$ and was adjusted to $120 \mathrm{~V}$ after a tracer dye entered the resolving gel. After electrophoresis, the gels were stained in the solution composed of $0.1 \%$ of Coomassie Brilliant Blue R-250, $1 \%$ of methanol solution and 1\% of acetic acid. The unstaining solution was composed of $1 \%$ of acetic acid and $1 \%$ of methanol.

MALDI-TOF analysis. Freeze-dried samples of the peaks from gel-filtration chromatography were used to Matrix-Assisted Laser Desorption Time of Flight Analysis (MALDI-TOF) on a Voyager-DE STR Bioworkstation (PerSeptive Biosystems). Samples were dissolved in 1.0\% aqueous trifluoroacetic acid and the matrix sinapinic acid was added. Then the solution was vortex mixied and $1.0 \mathrm{ml}$ of the sample solution was applied to the Voyager Bio-workstation sample plate and dried at room temperature. Spectrometer equipped with delayed-extraction system was operated in a linear mode. Sample ions were evaporated by irradiation with $\mathrm{N}_{2}$ laser at the wavelength of $337 \mathrm{~nm}$, and accelerated at $23 \mathrm{KV}$ potential in the the ion source with delay of $150 \mathrm{~ns}$. The samples were ionized with 100-200 shots of a 3ns pulse width laser light. The signal was digitized at a rate of $500 \mathrm{MHZ}$ and 
averaged data was submitted to a standard of voyager data system for manipulation. MALDI-TOF was calibrated using a Saquazyme calibration mixture (Applied Biosystems) consisting of bovine insulin (5,734 Da), E. coli thioredoxin (11,674 Da) and horse apomyoglobin (16,952 Da).

Amino acid sequence analysis. Protein was purified in polyacrylamide gel electrophoresis, and then transferred to PVDF membrane. the partial N-terminal amino acid sequence of KTI was detected by an automatic amino acid sequencer through automated Edman degradation. The percentage sequence identity with trypsin inhibitor from the other members of Kunitz family was determined using CLUSTAL W 2.1 and NCBI-BLAST.

\section{Results}

Purification of SKTI. Through grinding, phosphoric acid extraction, heat treatment and ammonium sulfate precipitation, $37.7 \mathrm{mg}$ of crude protein with $65.38 \mathrm{U} \cdot \mathrm{mg}^{-1}$ activity was obtained from $10 \mathrm{~g}$ soybean flour, and followed by the purified fraction came from DEAE-cellulose column as shown in Fig. 1. In the process of KTI purification, the crude extract was separated into four peaks by a linear gradient elution of 0-0.4 NaCl and peak I, II , III showed inhibitory activity (Fig. 1). Two peaks were obtained by affinity chromatography (shown in Fig. 2) and the fraction of peak II possessed of the anti-trypsin activity. Size exclusion on G-75 eluted two peaks (Fig. 3) with $4733 \mathrm{TIU} / \mathrm{mg}$ of the specific activity and $17.3 \%$ of the yield, as shown in Table 1.

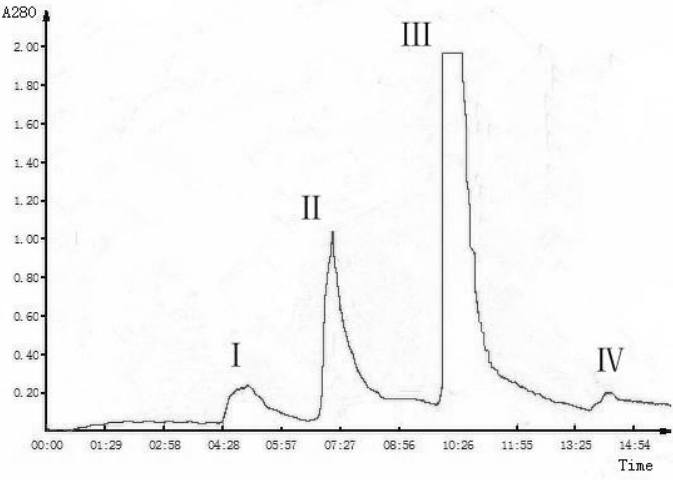

Figure 1. Ion-exchange chromatography on DEAE-52

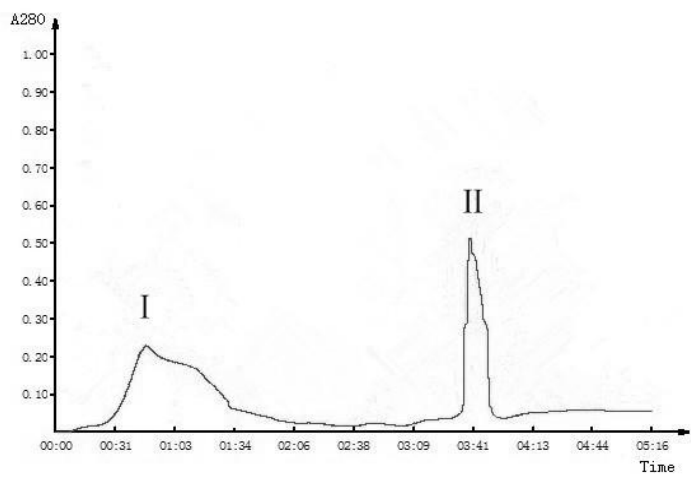

Figure 2. Affinity chromatography on trypsin-sepharose 4B column

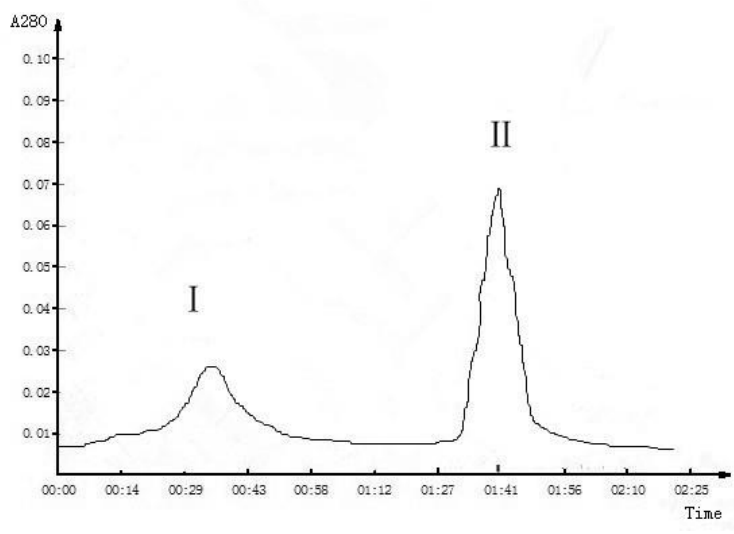

Figure 3. Gel filtration by sephadex G-75

The purification fold and yield of trypsin inhibitor from the soybean seeds was summarized in Table 1. The extract was firstly heated, and then purified by ammonium sulfate precipitation. $35-75 \%$ of ammonium sulfate saturation was proved to be the best recovery range of trypsin inhibitor according to the result of the experiment (data not shown). 
Table 1. Purification steps of KTI

\begin{tabular}{cccccc}
\hline Purification step & protein/mg & activity/U & $\begin{array}{c}\text { Specific } \\
\text { activity/U. } \mathrm{mg}^{-1}\end{array}$ & $\begin{array}{c}\text { Purification } \\
\text { fold }\end{array}$ & Yield/\% \\
\hline $\begin{array}{c}\text { Crud extract of STI } \\
\text { DEAE-Cellulose }\end{array}$ & 37.7 & 2465 & 65.38 & 1 & 100 \\
$\quad 17.8$ & 1743 & 97.92 & 1.50 & 70.7 \\
$\begin{array}{c}\text { Trypsin Sepharose } \\
\text { 4B column }\end{array}$ & 2.2 & 1617 & 735 & 11.24 & 65.6 \\
$\quad$ Sephadex G-75 & 0.09 & 426 & 4733 & 72.39 & 17.3 \\
\hline
\end{tabular}

After the crude sample passed DE-52 chromatographic column, 1.5 of purification fold and $70.7 \%$ of the yield were obtained (shown in Table 1). After the DE-52 active fraction was treated by trypsin Sepharose 4B, 11.24-fold purification of KTI was attained with a yield of 65.6\% (shown in Table 1). However, after the active fraction of trypsin Sepharose 4B passed Sephadex G-50 gel filtration, purification fold and the yield of KTI was increased by 61.15 and $17.3 \%$, respectively (shown in Table 1), meanwhile, a single band appeared on SDS-PAGE and the corresponding molecular mass was 19.4 kDa (Fig.4).

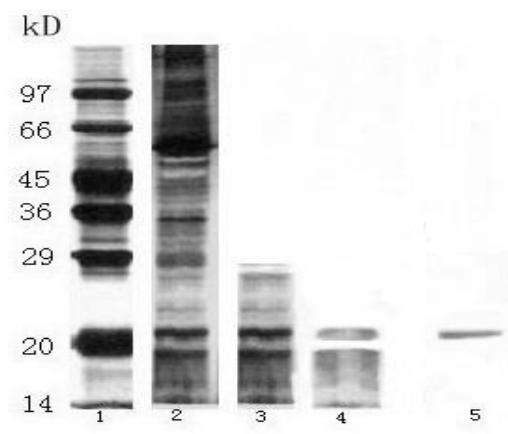

Figure 4. SDS-PAGE electrophoresis

Note: 1:Marker;2:crude extract with 10 times of dilution;3:active frcaction after DEAE-52;4:active frcaction after Trypsin-Sepharose-4B;5:active frcaction after Sephadex G-75.

MALDI-TOF analysis. The accurate molecular mass of KTI was calculated using MALDI-TOF (Fig. 5). a single-signal peak and a double-signal peak were shown at $\mathrm{m} / \mathrm{z}$ of $22907.51 \mathrm{Da}$ and 34166.67Da, respectively. This result suggested that accurate molecular mass of KTI was 22907.51Da and was similar to protease inhibitors of the Kunitz family.

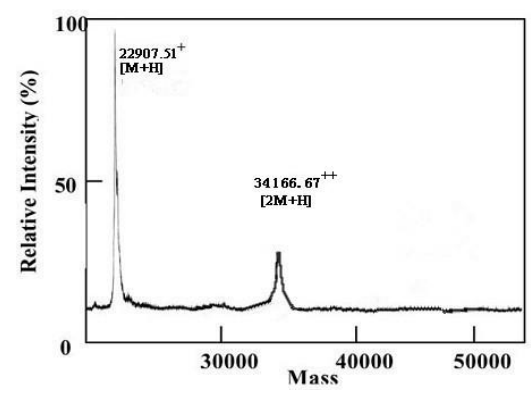

Figure 5. MALDI-TOF analysis of KTI

Determination of amino acid sequence of SKTI. Multiple sequence alignment of SKTI and KTI derived from the other legumes was performed by CLUSTAL W2.1, and many conserved amino acid 
residues were found, some of which were related to the function and structure of KTI (shown in Fig.6).

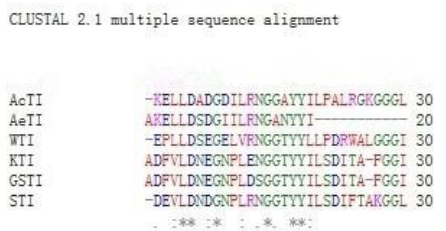

Figure 6. Partial sequences of soybean KTI aligned with different known Kunitz inhibitors

Note: AcTI, Acacia confusa trypsin inhibitor (AAB26177); AeTI, Archidendron ellipticum trypsin inhibitor (P84890.1); WTI, Psophocarpus tetraganolobus trypsin inhibitor (P10821); KTI, Glycine max Kunitz inhibitor (AAK20289); GSTI, Glycine soja Kunitz inhibitor (BAD04942); “* " indicated $100 \%$ of conserved region; " : " indicated the complete conserved amino acid residues; "."indicated no complete conserved amino acid residues; "-"indicated the deficiency.

The sequence (DEVLDNDGNPLRNGGTYYILSDIFTAKGGL) determined by automatic amino acid sequencer was searched on NCBI-BLAST, and it was found that to various degrees, SKTI had the homology with many KTI derived from the other legumes and the homology with KTI (Glycine $\max$ Kunitz inhibitor, AAK20289) was the highest, 88\%(Table 2).

Table 2. Amino sequence alignment of related Kunitz protease inhibitors

\begin{tabular}{cc}
\hline The origin of KTI & Identity $(\%)$ \\
\hline Glycine max & 88 \\
Glycine soja & 83 \\
AeTI & 79 \\
ACTI & 74 \\
WTI & 63 \\
\hline
\end{tabular}

\section{Discussions}

Separation of soybean trypsin inhibitor. Protease inhibitors existed in all legume belonged to small regulatory proteins and contained two types inhibitors, that is, Kunitz-type and Bowman-Birk-type inhibitor [17]. During the preparation of crude extracts, a large part of hybrid protein except trypsin inhibitor was eliminated through thermal denaturation, which could simplify the purification steps. Rackis [18] reported soybean trypsin inhibitor has a good thermal stability, even at $105^{\circ} \mathrm{C}$ for $10 \mathrm{~min}$, it still retains activity. Therefore, when prepared for crude extracts, we took heat treatment under $65^{\circ} \mathrm{C}$ to remove hybrid protein.

The solubility of various proteins in different salt concentrations is disparate, that is, different saturated salt solution makes different proteins precipitated. Based on this theory, the target protein was separated from other proteins, and during the process of salting out, protein had the maximum precipitation amount nearby its isoelectric point. Soybean trypsin inhibitor is an acidic protein, while ammonium sulfate is a salt of strong acid and weak base, and not only enables the protein to produce the salting-out effect, but also decreases $\mathrm{pH}$ value of the solution. So ammonium sulfate was chosen to salt out in this present experiment. During the preparation for crude extracts, we added ammonium sulfate to $35 \%-75 \%$ saturation in order to remove the alkaline or neutral hybrid protein. In addition, Prasad et al. [19] reported that 25-80\% of ammonium sulfate saturation could cause that the specific activity of protease inhibitors from the black gram seed was increased by 2.27 -fold. However, in the present study, after $35 \%-75 \%$ ammonium sulfate, proteins with the trypsin inhibitory activity of 65.38U. $\mathrm{mg}^{-1}$ were obtained. 
Purification of soybean Kunitz trypsin inhibitor. With in-depth study and broad application of soybean trypsin inhibitor, it is imperative to propose separation and purification methods of STI with ease, simpleness and high efficiency. Under this circumstance, many scholars both at home and abroad began to do specialized research on this work [11-13].

In the present experiment, according to the report of Mello et al. [20], most inhibitors in the Kunitz family are acidic, so we selected the anion exchange agent, DEAE cellulose -52 . The data showed that this treatment was very important for eliminating the excessive pigmentation of the crude extract, eliminated basically in the first peak (Fig.1).

However, gradient elution caused that the active fluid had higher salt concentration, so dialysis was used to remove the salt in the sample solution for the purpose of decreasing the impact of neutral salts on protein solubility. It was reported that STI can bind with trypsin specifically [21-23]. According to this characteristic, we used affinity chromatography, that is, trypsin was coupled with Sepharose 4B. After this step, specific activity of STI was increased rapidly and reached $772.11 \mathrm{U} / \mathrm{mg}$, and its purification fold was enhanced by 12.40 times. Its purification efficiency was much higher than that of ion exchange chromatography, which was proved by the result of electrophoresis (Fig. 4). Sephadex G-75 can separate proteins of different molecular weight. In addition, it was reported that when trypsin inhibitor from the adzuki bean seed was finally purified by gel filtration on Sephacryl S-200, specific activity of trypsin inhibitor was increased by 10.91-fold [24]. Based on the above reports, in the present study we selected Sephadex G-75 as the final purification. As a result, STI was purified by up to 72.39 times with specific activity of $4733 \mathrm{U} / \mathrm{mg}$. Compared with the results of Kang et al. [17], the purification effect of this study was significantly improved, and the process could be simply operated. It is indicated that the separation and purification methods used in this experiment have good popularization significance.

In addition, the results of SDS-PAGE showed a single protein band which accorded with the reported KTI molecular weight [25]. Furthermore, 22907.51Da of the accurate molecular mass of this inhibitor was obtained by determination of MALDI-TOF, which is consistent with the results of Kortt [26]. But these methods had low purification efficiency, therefore, our research continues to explore practical ways to purify KTI.

$\mathbf{N}$-terminal amino acid sequence analysis. Typical serine protease inhibitors from plants bind to serine protease via reactive sites of inhibitors and inhibit their activities. Zhang et al. analyzed the amino acid sequences of KTI from Genbank database, such as Glycine max, Adenanthera pavonina, Delonix regia, Enterolobium contortisiliquum, Bauhinia variegate by bioinformatic method and found that Leu, Gly, Glu, Val, Ser and Asp were abundant in those inhibitors [27]. In this study, we observed the similar results that the KTI was rich in residues of Gly, Asp, Leu, in addition, we also found three conserved residues (Ile, Val, Leu).

The recovery of amino acid sequence is important to characterization of the protein. Sequence alignment revealed that Kunitz protease inhibitors were highly homologous in plants. In this study, the N-terminal sequence analysis of KTI showed a strong similarity with other members of Kunitz protease inhibitors from the Papilionoideae subfamily[28-30] and KTI exhibited over 80\% sequence similarity with protease inhibitors of Glycine max and Glycine soja (Table.2). But due to various reasons, such as the completeness of the database, the precise of the instrument and sample pre-treatment, homology of the amino acid sequence can not completely reach $100 \%$.

\section{Acknowledgements}

The authors want to thank National Natural Science Foundation of China (NSFC, No.31000769), Postdoctoral Library of Jilin Agricultural University and Project funded by China Postdoctoral Sciemce Foundation (Grant, No.2012M520690) for the funding. 


\section{References}

[1] M. Richardson, Seed storage proteins: the enzyme inhibitors. In: Rogers, L. J. (Ed.), Methods in Plant Biochemistry, Amino Acids,Proteins and Nucleic Acids, 2ndEd.; Academic Press: New York, U.S.A. (1991)

[2] G. Francis, H. P. S. Makkar, B. K. Klaus, Antinutritional factors present in plant-derived alternate fish feed ingredients and their effects in fish, Aquaculture 199 (2001) 197-227.

[3] M. L. Kakade, Biochemical basis for the differences in plant protein utilization, J. Agric. Food Chem. 22 (1974) 550-555.

[4] M. Yamamoto, T. Ikenaka, Studies on soybean trypsin inhibitors1. Purification and characterization of two soybean trypsin inhibitors, J. Biochem. 62 (1967) 141-149.

[5] B. Kassell, Trypsin and chymotrypsin inhibitors from soybeans, Methods Enzymol. 19 (1970) 853-862.

[6] M. N. Gupta, S. Jain, I. Roy, Immobilized metal affinity chromatography without chelating ligands: purification of soybean trypsin inhibitor on zinc alginate beads, Biotechnol. Prog. 18 (2002) 78-81.

[7] S. X. Wan, J. Hua, W. W. Wang, S. P. Zhang, Research status of trypsin inhibitor in different fields, J. Beijing. Agric. Coll. 18 (2003) 152-155.

[8] F. D. Wen, J. R. Fu, Protease inhibitors and their physiological functions in plant seeds, Plant Phys. Commun. 1 (1997) 1-9.

[9] O. L. Franco, S. C. Dias, C. P. Magalhães, A. C. Monteiro, C. Jr. Bolch, F. R. Melo, O. B. Oliveira-Neto, R. G. Monnerat, M. F. Grossi-de-Sá, Effects of soybean Kunitz trypsin inhibitor on the cotton boll weevil, Phytochem. 65 (2004) 81-89.

[10] L. G. Buttle, A. C. Burrells, J. E. Good, P. D. Williams, P. J. Southgate, C. Burrells, The binding of soybean agglutinin (SBA) to the intestinal epithelium of Atlantic salmon, Salmo salar and Rainbowtrout, Oncorhynchus mykiss, fed high levels of soybean meal, Vet. Immunol. Immunopathol. 80 (2001) 237-244.

[11] G. C. Mello, M. L. Oliva, J. T. Sumikawa, O. L. Machado, S. Marangoni, J. C. Novello, M. L. Macedo, Purification and characterization of a new trypsin inhibitor from Dimorphandra mollis seeds, J. Protein Chem. 20 (2001) 625-631.

[12] J. J. Rackis, R. L. Anderson, Isolation of four soybean trypsin inhibitors by DEAE-Cellulose chromatography, J. Biochem. Biophys. Res. Commun. 15(1964) 320-335.

[13] R. Johnson, J. Narvaez, G. An, C. Ryan, Expression of proteinase inhibitors I and II in transgenic tobacco plants. Effects on natural defense against Manduca Sexta larvae, Proc. Natl. Acad. Sci. USA. 86 (1998) 9871-9875.

[14] M. A. Bradford, A rapid and sensitive method for the quantitation of microgram quantities of protein utilizing the principle of protein-dye binding, Anal. Biochem. 76 (1976) 248-254.

[15] U. K. Laemmli, Cleavage of structural proteins during the assembly of the head of bacteriophage T4, Nature 227 (1970) 680-685.

[16] M. L. Macedo, D. G. de Matos, O. L. Machado, S. Marangoni, J. C. Novello, Trypsin inhibitor from Dimorphandra mollis seeds: purification and properties, J. Phytochem. 54 (2000) 553-558.

[17]Z. Kang, J. Wang, N. H. Zhang, L. F. Du, Purification and some properties of a trypsin inhibitor from Spinacia oleracea L.seeds, Nat. Prod. Res. Develop. 17 (2005) 143-146. 
[18] J. J. Rackis, H. A. Sasame, R. K. Mann, R. L. Anderson, A. K. Smith, Soybean trypsin inhibitors: Isolation, Purification and Physical properties, Arch. Biochem. Biophys. 98 (1962) 475-477.

[19]E. R. Prasad, A. Dutta-Gupta, K. Padmasree, Purification and characterization of a Bowman-Birk proteinase inhibitor from the seeds of black gram (Vigna mungo), Phytochem. 71 (2010) 363-372.

[20] G. C. Mello, M. L. V. Oliva, J. T. Sumikava, O. L. Machado, S. Marangoni, J.C. Novello, M. L. Macedo, Purification and characterization of a new trypsin inhibitor from Dimorphandra mollis seeds, J. Protein Chem. 20 (2002) 625-632.

[21] C. L. Wang, Y. Z. Zhang, Z. G. Sun, Progress on the research of Bowman-Birk soybean trypsin inhibitor, J. Soy. Sci. 26 (2007) 757-760.

[22] Y. Birk, Purification and properties of a highly active inhibitor of trypsin and chymotrypsin from soybeans, J. Biochem. 54 (1961) 378-381.

[23] Y. H. Yu, Research status of trypsin inhibitor in feed, Feed Induct. 22 (2001) 1-4.

[24] S. Klomklao, S. Benjakul, H. Kishimura, K. Osako, M. Tanaka, A heat-stable trypsin inhibitor in adzuki bean (Vigna angularis): effect of extraction media, purification and biochemical characteristics, Int. J. Food. Sci. Technol. 45 (2010) 163-169.

[25] A. Bhattacharyya, S. Mazumdar, S. M. Leighton, C. R. Babu, A Kunitz proteinase inhibitor fromArchidendron ellipticum seeds: Purification, characterization, and kinetic properties, Phytochemistry 67 (2006) 232-241.

[26] A. A. Kortt, M. A. Jermyn, Acacia Proteinase inhibitors purification and properties of the trypsin inhibitors from Acacia elata seed, J. Biochem. 115 (1981) 551-557.

[27] Y. G. Zhang, Y. Huang, Y. J. Song, F. F. Chen, J. Y. Zhou, H. Liao, Bioinformatics Analysis of Kunitz Protease Inhibitors in Plants, Biotech. Bull. 12 (2011) 101-107.

[28] S. Onesti, P. Brick, D. M. Blow, Crystal structure of a Kunitz-type trypsin inhibitor from Erythrina caffra seeds, J. Mol. Biol. 217 (1991) 153-176.

[29] Y. Kouzuma, M. Suetake, M. Kimura, N. Yamasaki, Isolation and primary structure of proteinase inhibitors from Erythrina variegata (Linn.) var. Orientalis seed, Biosci. Biotechnol. Biochem. 56 (1992) 1819-1824.

[30] S. Terada, H. Katayama, K. Noda, S. Fujimura, E. Kimoto, Amino acid sequences of Kunitz family subtilisin inhibitors from seed of Canvalia lineate, J. Biochem. 115 (1994) 397-404. 